DOI: http://dx.doi.org/10.15688/jvolsu4.2016.2.10

UDC 94(560)

Submitted: 23.01 .2016

LBC 63.3(5Туц)

Accepted: 25.03 .2016

\title{
TURKEY IN SEARCH OF RELEVANT FOREIGN POLICY STRATEGY (2002-2016)
}

\section{Dayan R. Urmanov}

Postgraduate Student, Department of International Relations, Kazan (Volga region) Federal University

dayan.urmanov@tatar.ru

Kremlevskaya St., 18, 420008 Kazan, Russian Federation

\begin{abstract}
The main idea of this article is to describe the process of Turkish foreign policy evolvement during the rule of Justice and Development party (JDP). From weak economy and unstable political situation in 2001, JDP quickly formulated a new strategy of foreign policy and stabilized economy. In the article the Turkish foreign policy in the 21 st century is divided into several stages which respond to different international threats and circumstances. The first stage was a peacekeeping stage when Turkey tried to stabilize the situation near its borders and implement peace initiatives for the purpose to find new markets and allies. As a result, Turkey formulated a new strategy of foreign policy, called "Zero Problems Policy" which aimed to create a ring of friendly countries on the borders. On the second stage, Turkish foreign policy was more active - Turkey tried to balance among regional power centers and confront with one of the most powerful actors - Israel. Confrontation with Tel Aviv was a preface to the third stage, and today under the influence of "Arab Spring" and desire to change its role in international relations, Turkey refused "Zero Problems Policy" strategy and turned to a new aggressive and revanchist idea - neoOttomanism. Ankara tries to build a new regional set of rules where Turkey will play a leading role.
\end{abstract}

Key words: Turkey, Justice and Development Party, "Zero Problems Policy”, Middle East, “Arab Spring”.

УДК 94(560)

Дата поступления статьи: 23.01.2016

ББК 63.3(5Туц)

Дата принятия статьи: 25.03.2016

ТУРЦИЯ В ПОИСКЕ АКТУАЛЬНОЙ ВНЕШНЕПОЛИТИЧЕСКОЙ СТРАТЕГИИ (2002-2016 гг.)

\section{Даян Ренатович Урманов}

Аспирант кафедры международных отношений,

Казанский (Приволжский) федеральный университет

dayan.urmanov@tatar.ru

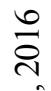

ул. Кремлевская, 18, 420008 г. Казань, Российская Федерация

$\hat{\overbrace{}}$

Аннотация. Статья посвящена исследованию актуальной темы, затрагивающей современный внешнеполитический курс Республики Турция и его эволюцию под руководством Партии справедливости и разви-

оै тия. Начав свою деятельность в 2001 г. в экономически и политически ослабленной стране, ПСР смогла ⿷匚⿱乛兀 статье поделена на ряд этапов, все они являются ответом на вызовы международной среды. Первый этап (?) характеризируется попыткой стабилизировать ситуацию вокруг себя и реализовать мирные инициативы с 
целью поиска новых стабильных рынков сбыта. Итогом первого этапа является возникновение стратегии внешней политики «Ноль проблем с соседями». На втором этапе внешняя политика Анкары активизируется, но продолжает сохранять баланс между центрами силы. На современном этапе развития турецкий курс отошел от политики «Ноль проблем с соседями» и под влиянием событий «Арабской весны» радикализировался и переориентировался на идеи неоосманизма.

Ключевые слова: Турция, Партия справедливости и развития, «Ноль проблем с соседями», Ближний Восток, «Арабская весна».

В преддверии президентских выборов в Египте был проведен опрос на тему: «Какую роль должен играть ислам в египетской политической системе?». Респондентам было дано на выбор 6 моделей - Саудовская Аравия, Иран, Турция, Тунис, Малайзия и Марокко. Согласно результатам опроса, 54 \% выбрали турецкую модель и $32 \%$ - Саудовскую Аравию [18]. Эти результаты совместно с результатами опросов, проведенных TESEV [18] в ряде Ближневосточных стран, показывают, что Турция под руководством Партии справедливости и развития (далее - ПСР) импонирует большинству населения в этом регионе. Это справедливо не только в отношении ПСР, но и ее лидера, Реджеп Тайип Эрдогана. Стремление к гибкости в отношениях с другими странами, а также привлекательность турецкой экономики - все это повлияло на позитивный имидж Турции. Необходимо понять, сможет ли Турция, до определенного времени казавшаяся политическим и экономическим оазисом в ближневосточном хаосе, стать лидером погрязшего в экономической и политической трясинах арабского мира в будущем.

Согласно политике «Ноль проблем с соседями» Анкара сумела установить новые отношения со своими соседями, увеличить товарооборот и активно развить политическое взаимодействие между странами. Турция продемонстрировала способность, не жертвуя национальной идентичностью и своими амбициями, сотрудничать как с Западом, так и с Востоком.

После развала Советского Союза для Турции открылось поле огромных возможностей, как политических, так и экономических, для реализации своих региональных геополитических амбиций. В их реализации внешняя политика ПСР опирается на союз с альянсом НАТО, на отношения с Европейским союзом (далее - ЕС) и на новых партнеров, преимущественно в Азии.

\section{Политика мира: 2002-2007}

Получив в 2002 г. в парламенте лишь 34 \%, ПСР старалась держаться осторожнее в первые годы и не давать причин для раздражения союзникам по НАТО [19]. Она поддержала рассмотрение в парламенте резолюции, разрешающей проход американских войск через территорию Турции для военной операции в Ираке (резолюция провалилась во многом из-за неопытности партии), и дала толчок новым реформам, направленным на присоединение к ЕС. Турция поддержала план генерального секретаря ООН Кофи Аннана по урегулированию Кипрского конфликта. На Ближнем Востоке Анкара использовала свои связи со всеми сторонами арабо-израильского конфликта, чтобы помочь мирному процессу. Вакуум, созданный начатой администрацией Буша войной в Ираке, позволил Турции играть роль посредника между Израилем и Сирией, и так же во многих других спорах, в том числе на Балканах и на Кавказе [7]. Помимо этого, активная внешняя политика была нужна новому турецкому правительству для самоутверждения перед претензией военной элиты, которая видела в действиях ПСР угрозу светскому обществу. Одной из причин согласия с планом Аннана по Кипру было желание создать у западных коллег репутацию руководства, с которым можно договариваться [10, р. 10],

Кроме того, в это время турецкая экономика начала стремительно набирать обороты, и ее экспорт, обусловленный масштабной реструктуризацией с начала 80-х гг., начал бить все рекорды. Более значимо и то, что экспортные операции, а также экономическое процветание было не продуктом одного или двух регионов, а успехом всей страны в целом. Регионы, находящиеся на Анатолийской периферии, активизировались в вопросе организации новых предприятий в Африке и в дру- 
гих частях мира. Так называемые «Анатолийские тигры», ведомые консервативными бизнесменами, являющимися основной опорой Партии справедливости и развития, добивались заметных успехов [19].

Турецкие лидеры объясняют цели и успех своей внешней политики соединением «мягкой силы», направленной на завоевание друзей, со своим стратегическим положением, историческими, культурными и экономическими связями с различными регионами.

\section{Политика балансирования: 2007-2011}

Этот период характеризуется попытками Турции усилить позиции в регионе и за его пределами. Первым делом Анкара попыталась в одностороннем порядке сбалансировать влияние Израиля в регионе. Одним из предпринятых шагов в данном направлении была поддержка Сирии, несмотря на серьезное давление со стороны международного сообщества, которому подвергался Дамаск. Турция также пыталась балансировать между различными иракскими фракциями. Ослабленные двумя войнами и множеством экономических проблем, США отказались от своей доминирующей роли на Ближнем Востоке [7].

Однако нельзя утверждать, что те значительные перемены во внешней политике Турции произошли во многом из-за внешних обстоятельств, хотя некоторые из исследователей считают, что ошибки израильского руководства способствовали эволюции внешней политики Анкары [22]. На самом же деле поворотным моментом было соперничество между гражданским и военным истеблишментом. Кульминацией этого конфликта с военными была победа ПСР на выборах 2007 года. Столкнувшись с угрозой прихода к власти основателя ПСР и действующего министра иностранных дел Турции Абдуллах Гюля, военное руководство страны начало неумелые попытки предотвратить избрание Абдуллах Гюля.

После уверенной победы с 47 \% на выборах ПСР могла использовать новые возможности во внешней политике, недоступные ей ранее. Первым делом она установила дружественные отношения с курдским правительством в Ираке, контакты с которым блокиро- вались предыдущим президентом, боявшимся, что этот прецедент северного Ирака скажется на поведении турецких курдов.

Поражение военных также означало, что ПСР больше не стоило беспокоиться о сговоре между военным истеблишментом Турции и правительством США.

Первой жертвой самостоятельности турецкой внешней политики стал Израиль. После операции в секторе Газа риторика Анкары по отношению к Тель-Авиву ужесточилась. В Давосе Эрдоган позволил себе встать и демонстративно уйти перед выступлением президента Израиля Шимона Переса. Отношения с Израилем окончательно испортились в 2010 г., когда израильские военные атаковали турецкое судно «Mavi Marmara», пытавшееся прорвать блокаду сектора Газа. Ошибка Израиля была в том, что на откровенную провокацию со стороны Турции они дали чересчур жесткий ответ, приведший к гибели девяти турок. Это укрепило позиции Анкары в регионе и сделало из Турции противовес Израилю. Поддержка, оказанная ХАМАСу, была в числе факторов, сделавших Эрдогана одним из самых почитаемых государственных деятелей в арабских странах [8].

Конфронтация с Израилем также изменила характер отношений между Турцией и США. Вашингтону было удобно, когда его ключевые союзники в данном регионе поддерживали тесные отношения. Во внутренней политике США американские евреи были известны как основные проводники турецкого влияния. До прихода к власти ПСР правительство Турции активно взаимодействовало с еврейским лобби в Вашингтоне с целью увеличения влияния Анкары, а также в качестве противовеса греческим и армянским лобби. Для предыдущих правительств это была вполне успешная политика, но для Эрдогана и ПСР никогда не было приятен тот факт, что отношения с США зависят от Израиля и доброй воли еврейского лобби в Вашингтоне [16]. Ряд неоспоримых преимуществ позволял турецкому руководству чувствовать себя более серьезным союзником США в данном регионе, нежели Израиль. Тель-Авив не мог похвастаться тем обилием политических и экономических связей на Ближнем Востоке, коими обладала Турция. Израильско-турецкий рас- 
кол позволил Анкаре перенастроить свои отношения с Вашингтоном и позволил администрации Обамы эффективно разделить свои отношения с обоими союзниками.

Совместно со своей риторикой и действиями, включающими возможное охлаждение отношений с Израилем, Турция формирует в регионе свой новый образ сильного государства, противостоящего Израилю. При этом Турции играет на руку и то, что она является членом НАТО.

Турция старалась по-новому строить отношения не только с Израилем. В мае 2010 г. Турция подписывает соглашение с Бразилией в Тегеране, которое оценивается Вашингтоном как подрывающее достигнутое по этому вопросу решение ООН. Наряду с временным ухудшением турецко-американских отношений и голосованием в Совете Безопасности ООН против своего союзника действия Турции сказываются положительно на ее образе в регионе [9].

\section{Стремление стать}

\section{региональным гегемоном: 2011-2015}

В начале активных потрясений на севеpe Африки и в ряде ближневосточных стран, названных «Арабской весной», Турция показывает неуверенность и некие сомнения относительно развивающегося протестного движения. Однако со временем Анкара меняет позицию относительно происходящих событий и пытается использовать «Арабскую весну» в качестве возможности утвердиться на международной арене. В этот период можно отследить резкую смену риторики Анкары по отношению к происходящим событиям, от сдержанно-нейтральной она переходит к попыткам навязать свое видение происходящих событий тем новым силам, которые приходят к власти в ходе событий «Арабской весны». Это выражается в том, как ведет себя Анкара по отношению к ситуации в Сирии. Показательной в этом плане стала речь министра иностранных дел Турции Ахмета Давутоглу перед парламентом, в которой он заявил: «Отныне Турция должна возглавить движение перемен на Ближнем Востоке. Мы будем продолжать оставаться на гребне этой волны. Это новый Ближний Восток, и мы должны быть там хозяевами, лидерами и слугами, независимо от того, что скажут другие, новым лидером и оратором будет Турция» [13].

Весной 2011 г. «Арабская весна» застала мировое сообщество врасплох. Для Турции эти события означали полный поворот внешнеполитического курса. Знаменитая политика «Ноль проблем с соседями» помогла установить хорошие отношения со многими региональными диктаторами, кроме, пожалуй, $\mathrm{X}$. Мубарака. Турция была заинтересована в расширении коммерческих возможностей для бурно развивающейся турецкой экономики, и поэтому для того, чтобы делать бизнес в странах, где рынок косвенно или напрямую контролировался режимом, надо было подружиться с этим режимом. Таким образом, турки стали в некоем роде зависимы от существующей системы власти в данном регионе.

Такое положение дел не устраивало Египет и Саудовскую Аравию, для них Анкара с ее внешней активностью представляла угрозу, поэтому в Египте уход Мубарака полностью устраивал Эрдогана. Помимо этого, в 2010 г. Каир не стал поддерживать Турцию в конфликте с Израилем, и в 2011 г. Эрдоган был одним из первых, кто заявил о том, что Мубарак должен уйти [6].

Анкара почувствовала затруднения лишь тогда, когда волна беспорядков докатилась до Ливии. У Турции на тот момент там работало около 25000 рабочих и имелось около 15 млрд долл. инвестиций. Ливийский политический лидер М. Каддафи и Эрдоган сумели построить тесные отношения [16]. Падение ливийского режима было серьезным ударом для Турции, и поначалу Анкара возражала против участия сил НАТО в ливийской гражданской войне. В отличие от ситуации в Египте, Анкара в Ливии сомневалась. Наконец поняв, что ливийскому режиму не выстоять, Анкара делает резкий поворот на 180 градусов и начинает активно поддерживать смену режима.

Вслед за кризисом в Ливии последовали волнения в Сирии. Ливия была прибыльным рынком с большим количеством нефтедолларов, Сирия же была витриной политики «Ноль проблем с соседями». Отношения Дамаска и Анкары прошли путь от враждебности до тесной дружбы, Асад и Эрдоган стали близкими друзьями. Турция и Сирия в период с 2000 по 
2011 г. подписали ряд документов: это соглашения о совместной борьбе с терроризмом, избежании двойного налогообложения, взаимной защите инвестиций, сотрудничестве таможенных служб, а также в области здравоохранения, развития железнодорожного, морского и воздушного транспорта, об отмене визового режима. Кроме того, были подписаны протоколы о взаимодействии в энергетике, жилищном строительстве, туризме, перевозке грузов. Сирия была первым государством, с кем Турция подписала договор о свободной торговле. Контакты двух стран стали настолько обширными, что турки говорили: «у двух народов одно правительство». Но со временем протестное движение охватило и Сирию, однако турки уже извлекли урок из ливийской войны. «Арабская весна» оказалась неостановимым импульсом, и турки почти сразу же отказались от Асада, но перед этим попытались уговорить партию БААС провести ряд значимых реформ внутри страны. Эрдоган, учитывая то, сколько Турция вложила в отношения с Дамаском, пытался уговорить Сирию пойти на реформы, но Асад не прислушался [11].

Турки посчитали, что режим Асада обречен и что в скором времени все пойдет по египетскому и ливийскому сценарию. Более того, учитывая тесные связи, сложившиеся между двумя странами, Анкара решила, что отказ в поддержке Дамаска лишь ускорит его падение. Однако режим оказался довольно устойчивым, никто за пределами Сирии не ожидал, что у режима будут силы держаться так долго.

Для США Анкара - незаменимый союзник по сирийскому вопросу. Сегодня Турция единственный сосед Сирии, который имеет возможность играть значительную роль в решении данного кризиса, будь то размещение большого количества беженцев или же предоставление своей территории для военного вмешательства. Помимо вышесказанного, тот факт, что Турция в прошлом активно поддерживала сирийский режим и при начале протестных событий в Сирии стала, наоборот, активно содействовать падению режима Асада, является мощным психологическим ударом для Дамаска [14].

Позиция, которую заняла Турция в данном вопросе, объясняется соображением внутренней политики, в частности, учетом курдской проблемы. В случае с курдским меньшинством Анкара активно работает на этом направлении, и последним успехом турецкой внутренней политики стало заявление лидера Рабочей партии Курдистана А. Оджалана: «Пришла пора замолчать оружию, перестанет литься кровь турецкого и курдского народов. Складывайте оружие. Мы совершаем переход от вооруженной борьбы к борьбе демократической» [15].

В случае с противостоянием с военным истеблишментом ПСР смогла окончательно решить вопрос в 2011 г., вынеся на референдум новые поправки к конституции, которые фактически лишали военных прежнего влияния. Проблема с оппозиционными силами теряет остроту, оппозиция сегодня лишена лидера и не знает, куда ей двигаться.

Во внешней обстановке многие факторы также благоприятствуют Турции, кризис еврозоны позволяет Эрдогану говорить об успешности турецкой модели развития экономики, показывающей один из самых высоких показателей роста на сегодня, и, основываясь на этом, Анкара становится неким компромиссным вариантом для арабских стран.

Кроме того, роль Турции в Сирии и Ираке в силу ее географических и политических особенностей является одной из ключевых, что делает ее незаменимым партнером на Ближнем Востоке для США и Европейского союза.

Стабильный Ближний Восток, несомненно, является приоритетом внешней политики Анкары. Конфликты в данном регионе в форме гражданской войны, межэтнических и межклановых столкновений грозят перекинуться на территорию Турции, ее экономика нуждается в стабильном и процветающем Ближнем Востоке, чтобы экспортировать туда свои товары.

Анкаре приходится вести себя очень осторожно с Ираном. С одной стороны, две страны занимают диаметрально противоположные позиции по сирийскому и иракскому вопросам, с другой стороны, Иран понимает, что позиция правительства ПСР полезна в ядерном вопросе для Тегерана [21]. Тем не менее, важно понимать, что при дальнейшей эскалации конфликтов в регионе он подвергнется неподконтрольному взрыву насилия и 
нестабильности. Ливан также не останется в стороне. В свою очередь, это подорвет доверие к Турции и приведет к снижению иностранных инвестиций и туристического потока. Сколько бы Турция не пыталась ассоциировать себя с европейским государством, факт остается фактом: Турция граничит с тремя самыми нестабильными странами на Ближнем Востоке.

Основой современной турецкой внешней политики является работа «Стратегическая глубина» турецкого «Киссинджера» А. Давутоглу, некогда министра иностранных дел, а ныне - премьер-министра Турции. В своей работе он критикует современные подходы к внешней политике, считая их лишенными стратегического планирования, предлагает опираться на историческую силу турецкого народа и руководствоваться стратегическим и долгосрочными планами. Его не устраивает роль Турции в качестве «моста» между Европой и Азией, он считает Турцию и европейской, и азиатской, и кавказской, и балканской, и ближневосточной, и средиземноморской страной. Вот, что говорил сам А.Давутоглу о будущем Турции выступая перед членами ПСР: «Мы - неоосманы. Мы вынуждены заниматься соседними странами. И даже идем в Африку. Существует наследие, оставленное Османской империей. ...великие державы наблюдают за этим с растерянностью. Прежде всего, Франция пытается понять, зачем мы работаем в Африке. Я уже дал поручение: в какую бы африканскую страну не поехал Саркози, нужно, чтобы каждый раз, поднимая глаза, он видел здание турецкого посольства, турецкий флаг. Я дал указание арендовать посольства в самых лучших местах» [5].

На основе проведенного анализа можно сделать следующие выводы. С одной стороны, необходимо отметить ту разнонаправленность турецкой внешней политики, которая была достигнута в XXI веке. Начав с политики налаживания добрососедских отношений, Анкара сегодня играет все более значимую роль в решении широкого спектра вопросов мировой повестки: в Европе с помощью Анкары пытаются решить миграционный кризис; на Кавказе Турция активно вовлечена в решение армяно-азербайджанских противоре- чий; на Ближнем Востоке без нее невозможно наладить мирный процесс; в Центральной Азии Турция активно «разыгрывает карту» культурной близости, вовлекая тюркоязычные страны в орбиту своего влияния; инвестиционная и образовательная активность Турции в Африке сегодня уже не вызывает удивления, а, скорее, воспринимается как данность. С другой стороны, возникший пласт проблем в виде конфликта с курдским меньшинством расколовшегося турецкого общества, невнятной позиции по отношению к террористической организации ИГИЛ, конфликта с Российской Федерацией, упущенной возможности вступления в Европейский союз ведет к риску отказа от политики построения государства на основе оттоманского прошлого в пользу исламизации страны.

\section{СПИСОК ЛИТЕРАТУРЫ}

1. Дружиловский, С. Б. Внутренние факторы формирования внешней политики Ирана и Турции / С. Б. Дружиловский // Вестник МГИМО-Университета. -2010. - № 1 (10). - С. 166-177.

2. Карякин, В. В. Современная геополитическая динамика Ближнего и Среднего Востока / В. В. Карякин. - М. : Граница, 2010. -250 с.

3. Малышева, Д. Б. Новая ближневосточная стратегия Турции / Д. Б. Малышева // Россия и мусульманский мир. - 2012. - № 10. - С. 108-114.

4. Надеин-Раевский, В. А. Внешняя политика Турции: ветер перемен / В. А. Надеин-Раевский // Мировая экономика и международные отношения. -2013 . - № 2. - С. 84-92.

5. Ситуация в Турции: ноябрь 2009 г. // Институт Ближнего Востока. - Электрон. текстовые дан. - Режим доступа: http://www.iimes.ru/rus/stat/ 2009/03-12-09.htm (дата обращения: 24.01.2015). Загл. с экрана.

6. Турция на подъеме (22.10.2011) // Россия в глобальной политике. - Электрон. текстовые дан. Режим доступа: http://www.globalaffairs.ru/number/ Turtciya-na-podeme-15362 (дата обращения: 24.01.2015). - Загл. с экрана.

7. Aaron, S. S. Turkey's New Foreign Policy: Davutoglu, the AKP and the Pursuit of Regional Order / S. S. Aaron // Routledge. - 2015. - P. 54-98.

8. Albright, M. K. U.S. Turkey Relations A New Partnership / M. K. Albright, S. J. Hadley // Council on Foreign Relations Press. -2012. - P. 12-34.

9. Bülent, A. Davutoğlu Era in Turkish Foreign Policy/ A. Bülent // SETA PolicyBrief. - 2009. - №32.P. 16. 
10. Cagaptay, S. The Rise of Turkey: The TwentyFirst Century's First Muslim Power / S. Cagaptay // Bozorg Press. - 2014. - P. 278-311.

11. Cagaptay, S. Turkish Foreign Policy under the AKP: The Rift with Washington / S. Cagaptay // The Washington Institute for Near East Policy. - 2011. P. $8-15$.

12. Is Turkey Really at the Table? (24.11.2014) // Council on Foreign Relations. - Electronic text data. - Mode of access: http://www.cfr.org/turkey/ turkey-really-table/p37396 (date of access: 24.01.2015). - Title from screen.

13. Keyman, F. E. Democracy, Identity and Foreign Policy in Turkey: Hegemony Through Transformation / F. E. Keyman, S. Gumüsçu // Palgrave Macmillan. 2014. - P. 131-168.

14. Meclis'te gergin Suriye oturumu (26.04.2012) // Radikal. - Electronic text data. - Mode of access: http://www.radikal.com.tr/politika/mecliste-gerginsuriye-oturumu-1086125/(date of access: 24.01.2015). Title from screen.

15. Obama's Options in Damascus (16.08.2011) // Foreign Affairs. - Electronic text data. - Mode of access: https://www.foreignaffairs.com/articles/ turkey/2011-08-16/obamas-options-damascus (date of access: 24.01.2015). - Title from screen.

16. Öcalan Türk halkına seslenebilmeli (30.03.2013)// Radikal. - Electronic text data. - Mode of access: http://www.radikal.com.tr/politika/ocalanturk-halkina-seslenebilmeli-1127382/ (date of access: 24.01.2015). - Title from screen.

17. Turkey and the Arab Spring: Implications for Turkish Foreign Policy from a Transatlantic Perspective (Mediterranean Paper Series) / Ö. Taş̧ınar, H. J. Barkey, E. Soler i Lecha, H. Nafaa // German Marshall Fund. - 2011. - P. 32-45.

18. Turkey Is Pioneering a New Model of Democracy in the Middle East (10.01.2015) // Council on Foreign Relations. - Electronic text data. - Mode of access: http://www.cfr.org/turkey/turkeypioneering-new-model-democracy-middle-east/p36650 (date of access: 24.01.2015). - Title from screen.

19. Türkiye Dış Politikası için bir Test: Suriye Kriz (01.06.2012)// TESEV. - Electronic text data. - Mode of access: http://tesev.org.tr/tr/yayin/turkiye-dispolitikasi-icin-bir-test-suriye-krizi/ (date of access: 24.01.2015). - Title from screen.

20. Turkmen, I. Turkey's Today and Tomorrow / I. Turkmen // Wise Men Center for Strategic Studies. Bilgesam Publications. - 2009. - № 32. - P. 33.

21. Umit, C. Secular and Islamic Politics in Turkey: The making of the Justice and Development party / C. Umit // Routledge. - 2008. - P. 180-198.

22. William, B. Quandt. Troubled Triangle: The United States, Turkey, and Israel in the New Middle East / Quandt B. William// Just World Books. -2011. - P. 160.

\section{REFERENCES}

1. Druzhilovskiy S.B. Vnutrennie faktory formirovaniya vneshney politiki Irana i Turtsii [Internal Factors of Foreign Policy of Iran and Turkey]. Vestnik MGIMO-Universiteta, 2010, no. 1(10), pp. 166-177.

2. Karyakin V.V. Sovremennaya geopoliticheskaya dinamika Blizhnego i Srednego Vostoka [Contemporary Geopolitical Dynamics of the Middle East]. Moscow, Granitsa Publ., 2010.250 p.

3. Malysheva D.B. Novaya blizhnevostochnaya strategiya Turtsii [The Turkish New Middle East Policy]. Rossiya i musulmanskiy mir, 2012, no. 10, pp. 108-114.

4. Nadein-Raevskiy V.A. Vneshnyaya politika Turtsii: veter peremen [Turkey's Foreign Policy: the Wind of Change]. Mirovaya ekonomika $i$ mezhdunarodnye otnosheniya, 2013, no. 2, pp. 84-92.

5. Situatsiya v Turtsii: noyabr $2009 \mathrm{~g}$. [Situation in Turkey: November 2009]. Institut Blizhnego Vostoka [The Middle East Institute]. Available at: http:// www.iimes.ru/rus/stat/2009/03-12-09.htm (accessed January 24, 2015).

6. Turtsiya na podyeme (22.10.2011) [Turkey Is Growing (October 22, 2011)]. Rossiya v globalnoy politike [Russia in Global Affairs] Available at: http:// www.globalaffairs.ru/number/Turtciya-na-podeme15362. (accessed January 24, 2015).

7. Aaron S.S. Turkey's New Foreign Policy: Davutoglu, the AKP and the Pursuit of Regional Order. Routledge, 2015, pp. 54-98.

8. Albright M. K., Hadley S. J. U.S.-Turkey Relations: A New Partnership. Council on Foreign Relations Press, 2012, pp.12-34.

9. Bülent A. Davutoplu Era in Turkish Foreign Policy. SETA Policy Brief, 2009, no. 32, p. 16.

10. Cagaptay S. The Rise of Turkey: The TwentyFirst Century's First Muslim Power. Bozorg Press, 2014, pp. 278-311.

11. Cagaptay S. Turkish Foreign Policy under the AKP: The Rift with Washington. The Washington Institute for Near East Policy, 2011, pp. 8-15.

12. Is Turkey Really at the Table? (24.11.2014). Council on Foreign Relations. Available at: http:// www.cfr.org/turkey/turkey-really-table/p37396. (accessed January 24, 2015).

13. Keyman F.E., Gumüsçu S. Democracy, Identity and Foreign Policy in Turkey: Hegemony Through Transformation. Palgrave Macmillan, 2014, pp. 131-168.

14. Meclis'te gergin Suriye oturumu (26.04.2012). Radikal. Available at: http://www.radikal.com.tr/ politika/mecliste-gergin-suriye-oturumu-1086125. (accessed January 24, 2015).

15. Obama's Options in Damascus (16.08.2011). Foreign Affairs. Available at: https:// 
www.foreignaffairs.com/articles/turkey/2011-08-16/ obamas-options-damascus. (accessed January 24, 2015).

16. Öcalan Türk halkına seslenebilmeli (30.03.2013). Radikal. Available at: http:// www.radikal.com.tr/politika/ocalan-turk-halkinaseslenebilmeli-1 127382/. (accessed January 24, 2015).

17. Taşpınar Ö., Barkey H. J., Soler i Lecha E., Nafaa H. Turkey and the Arab Spring: Implications for Turkish Foreign Policy from a Transatlantic Perspective (Mediterranean Paper Series). German Marshall Fund, 2011, pp. 32-45.

18. Turkey Is Pioneering a New Model of Democracy in the Middle East (10.01.2015). Council on Foreign Relations. Available at: http://www.cfr.org/ turkey/turkey-pioneering-new-model-democracymiddle-east/p36650 (accessed January 24, 2015).

19. Türkiye Dış Politikası için bir Test: Suriye Kriz (1.06.2012). TESEV. Available at: http://tesev.org.tr/tr/ yayin/turkiye-dis-politikasi-icin-bir-test-suriye-krizi/. (accessed January 24, 2015).

20. Turkmen I. Turkey's Today and Tomorrow Wise Men. Center for Strategic Studies. Bilgesam Publications, 2009, no. 32, p. 33.

21. Umit C. Secular and Islamic Politics in Turkey: The making of the Justice and Development Party. Routledge, 2008, pp. 180-198.

22. William, B. Quandt. Troubled Triangle: The United States, Turkey, and Israel in the New Middle East. Just World Books, 2011, p. 160. 